
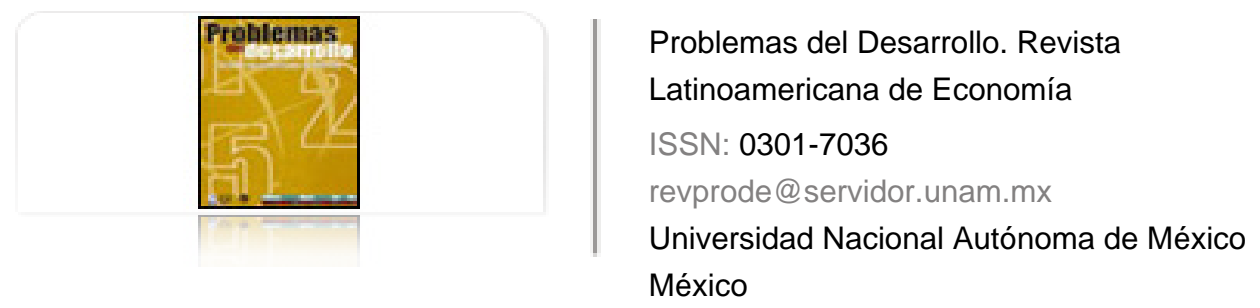

Ramírez Cedillo, Eduardo

POR UNA POLÍTICA FISCAL CONTRACÍCLICA

Problemas del Desarrollo. Revista Latinoamericana de Economía, vol. 37, núm. 147, octubre-

diciembre, 2006, pp. 81-107

Universidad Nacional Autónoma de México

Distrito Federal, México

Disponible en: http://www.redalyc.org/articulo.oa?id=11820100004

- Cómo citar el artículo

- Número completo

- Más información del artículo

Página de la revista en redalyc.org

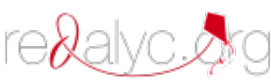

Sistema de Información Científica

Red de Revistas Científicas de América Latina, el Caribe, España y Portugal

Proyecto académico sin fines de lucro, desarrollado bajo la iniciativa de acceso abierto 


\section{POR UNA POLÍTICA FISCAL CONTRACÍCLICA}

\section{Eduardo Ramírez Cedillo*}

Fecha de recepción: 12 de enero de 2006. Fecha de aceptación: 5 de septiembre de 2006.

Resumen

La postura fiscal de las economías latinoamericanas y de muchas en desarrollo ha mantenido un carácter procíclico que ha jugado un papel importante en la inestabilidad que observan éstas, a diferencia de lo que sucede en los países desarrollados, que utilizan su política fiscal para atenuar las presiones del ciclo económico. A este respecto, en este trabajo se vierten algunas explicaciones, como: la exposición a la volatilidad de los capitales financieros y el uso inadecuado de la política de gasto en tiempos de auge, que impide que en momentos de recesión se pueda incrementar y manejarse contracíclicamente. En este documento, mediante la utilización del filtro Hodricky Prescott (1997), se demuestra la prociclidad de la política fiscal en el periodo 1980-2004 para México, y se asume que mientras se siga manteniendo una política de finanzas públicas sanas ésta se sostendrá en el mismo sentido. Adicionalmente, se propone una alternativa mediante la cual se lograría una política fiscal de postura contracíclica.

Palabras clave: politica fiscal, ciclo económico, finanzas públicas, volatilidad, empleo público.

\section{Abstract}

The fiscal stance of the Latin American economies and many developing economies has maintained a pro-cyclical character which has played an important role in the instability they experience, unlike what happens in the developed countries, which utilize their fiscal policy to limit the pressures from the economic cycle. In this respect, the study enunciates some explanations, such as exposure to the volatility of financial capital and the inadequate use of spending policy in times of economic boom, impeding its increase in periods of recession and its counter-cyclical management. In the present study, using the Hodrick-Prescott filter (1997), the pro-cyclicality of fiscal policy in the period 1980-2004 is demonstrated for Mexico, and it is assumed that while a healthy public finance policy was maintained, it was oriented in the same direction. In addition, an alternative is proposed in which a counter-cyclical fiscal policy is operated.

Key words: fiscal policy, economic cycle, public finances, volatility, public employment.

* Doctorante de Economía, Facultad de Economía UnAm. Correos electrónicos: ramceed@prodigy.net.mx y ramceed@hotmail.com 
Résumé

La posture fiscale des économies latino-américaines, et de beaucoup d'autres en développement, a conservé un caractère pro-cyclique qui a joué un rôle important dans leur instabilité, à la différence de ce qui se passe dans les pays industrialisés qui utilisent leur politique fiscale pour atténuer les pressions du cycle économique. Ce travail en fournit quelques explications comme l'exposition à la volatilité des capitaux financiers et l'adoption durant les périodes d'apogée d'une politique de dépense, qui empêche qu'elle puisse être augmentée et gérée de manière contre-cyclique en cas de récession. Dans ce document, il est fait recours au filtre d'Hodrick et Prescott (1997) pour démontrer le caractère pro-cyclique de la politique fiscale mexicaine entre 1980 et 2004, et il est considéré que celui-ci se perpétuera tant que se poursuivra une politique de finances publiques saines. Par ailleurs, une alternative est proposée, qui permettrait une politique fiscale à caractère contre-cyclique.

Mots-cléfs: politique fiscale, cycle économique, volatilité, emploi public.

Resumo

A postura fiscal das economias latino-americanas y de muitas em desenvolvimento mantém um caráter procíclico que tem jogado um papel importante na instabilidade que estas observam, diferente do que sucede nos países desenvolvidos que utilizam a sua política fiscal para atenuar as pressões do ciclo econômico. A esse respeito, neste trabalho vertem-se algumas explicações, como: a exposição à volatilidade dos capitais financeiros e o uso inadequado da política de gasto em tempos de auge, que impede que em momentos de recessão possa se incrementar e manejar contracíclicamente. Neste documento, com a utilização do filtro Hodrick y Prescott (1997), se demonstra a prociclicidade da política fiscal no periodo 1980-2004 para o México, e se assume que enquanto se mantiver uma política de finanças públicas saudáveis esta se sustentará no mesmo sentido. Adicionalmente, propõe-se uma alternativa com a qual se lograria una política fiscal de postura contracíclica.

Palavras chave: politica fiscal, ciclo econômico, finanças públicas, volatilidade, emprego público. 


\section{Introducción}

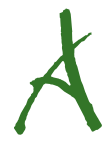

raíz del fracaso de las políticas de estabilización en materia de crecimiento y desarrollo económico en países emergentes (Davidson, 2003; Ffrench-

Davis, 2003), se ha empezado a mencionar la necesidad de instrumentar políticas económicas de corte contracíclico (Ocampo, 2001 y 2005; Budnevich, 2002; Lora y Panizza, 2002; Sánchez, 2003; Stiglitz, 2003; Braun y Di Gresia, 2003; Weeks y Roy, 2004) para disminuir la inestabilidad del sistema de producción capitalista. En los países desarrollados, de acuerdo con Stiglitz (2003), se ha observado que los periodos de recesión se han acortado mientras que los de expansión se han alargado, a diferencia de lo que pasa en las naciones subdesarrolladas. La razón es que, mientras en los primeros se llevan a cabo políticas contracíclicas, en las otras tal parece que han operado políticas procíclicas que incrementan los periodos de recesión e impiden salir de los mismos. ${ }^{1}$

Aun cuando el reconocimiento de la función contracíclica de la política económica es un buen avance, no es suficiente. De nada sirve saber que se tiene que ir en determinado sentido si se sigue operando con los mismos paradigmas de disciplina fiscal, autonomía de los bancos centrales, liberalización económica y financiera, entre otros. En ese contexto, la pérdida de una política soberana impide que los gobiernos de los estados nacionales puedan actuar en la satisfacción de las necesidades de sus habitantes. ${ }^{2}$ Resulta paradójico seguir manteniendo la estabilidad de precios con las propuestas de las instituciones financieras internacionales y, al mismo tiempo, intentar la estabilización de la economía real a la Keynes, como lo apunta Willianson (2004a), ${ }^{3}$ ya que el control de la inflación se ha logrado con el uso de

1 En el caso de la política fiscal procíclica instrumentada por América Latina, ésta es documentada por Gavin y Perotti (1997) de manera profunda. Los autores destacan cómo las naciones en desarrollo han operado con políticas contracíclicas a diferencia de lo acontecido en los países latinoamericanos.

2 Por lo que se asume que el incremento en la democracia es un elemento clave para mejorar la condición de los individuos. Considerando la democracia como un amplio conjunto que no se limite a la elección de los representantes sino que, adicionalmente, se pueda tener injerencia en materia de acciones económicas (Ocampo, 2001). Panizza y Yáñez (2005) presentan un estudio donde concluyen que una de las principales razones que tienen los latinoamericanos para estar en desacuerdo con las reformas consiste en la situación económica que se ha derivado de ellas, opinión también sustentada por estudios como el de Lora et al. (2004).

3 Willianson (2004b) menciona que sin dejar la disciplina fiscal es necesario usar la política fiscal como herramienta contra los vaivenes del ciclo económico, pero argumenta que tan 
políticas económicas restrictivas que son contrarias al pensamiento keynesiano: no se puede seguir exigiendo la disciplina fiscal ${ }^{4}$ y querer que la política fiscal sea contracíclica.

De acuerdo con Keynes (2003:353-354), es necesario hacer una diferencia entre el déficit corriente y el de capital, dejar que este último funcione en forma contracíclica (Cámara Neto y Vernengo, 2004) sin que su financiamiento se ciña únicamente a la captación de ingresos porque, a diferencia del planteamiento presentado por Seccareccia (2004), en el cual establece que la cuenta corriente debe arrojar el superávit que permita el déficit de capital, se asume que éste no tiene que ser compensado con la disminución del gasto corriente. Es decir, que el gobierno no necesita disminuir aquel para poder incrementar su gasto de capital; aceptar lo contrario es volver a situarse en el paradigma de finanzas públicas sanas.

La perspectiva desde la cual se considera conveniente transferir los ahorros de la cuenta corriente a la de capital consiste en considerar los rendimientos que genera la segunda. Sin embargo, en el caso de México, desde la década de los ochenta, se dio en mayor medida la reducción del gasto de capital y los ahorros generados se destinaron al pago de la deuda externa, misma que posteriormente sería amortizada con buena parte de los recursos generados por el proceso de privatización de empresas del Estado. El problema es que, a la fecha, se sigue incitando a la disminución del gasto corriente y a la venta de empresas públicas, sin que ello se pueda interpretar como un incremento en el gasto de capital.

Si la política fiscal en América Latina, y en especial México, dejó de funcionar como herramienta o alternativa de crecimiento, fue por supeditarla a los objetivos de estabilización monetaria. Ésta exige trabajar con disciplina fiscal, para lo cual se precisa que el gobierno trabaje con finanzas públicas en equilibrio, básicamente disminuyendo el gasto presupuestal ante la imposibilidad de incrementar los ingresos tributarios. La capacidad de la política fiscal para funcionar como estabilizador del ciclo económico se ve así reducida e incluso tiende a funcionar de manera procíclica. A decir de Clavijo (2000), la débil carga fiscal y la falta de instrumentos monetarios impidieron intentar una política económica aunque fuera tímidamente contracíclica, y he aquí de nuevo un problema de concepción: no se puede instrumentar una política contracíclica sin incurrir en déficit; en ese sentido, no es

sólo es posible hacerlo con estabilizadores automáticos y al inicio de un boom económico. En desacuerdo con Willianson, se piensa que es poco probable que un país pueda salir de un periodo recesivo de manera endógena manteniendo la disciplina fiscal, y dado que no se pretende abandonarla se antepone que los estabilizadores automáticos tan sólo podrían servir en el auge, ya que su aplicación en la parte descendente del ciclo conduce a déficit.

4 La disciplina fiscal, a diferencia de lo que piensan los economistas ortodoxos, no evita las crisis en la cuenta corriente ni produce pleno empleo en el sistema económico (Davidson, 2003). Por tanto, seguir el dogma no garantiza el equilibrio externo ni condiciones de crecimiento. 
necesario argumentar la debilidad de ingresos, los tributarios en una recesión serán bajos porque tienden a un comportamiento procíclico, y ante esa eventualidad el déficit presupuestal tendrá que aparecer.

El déficit fiscal que violenta la disciplina y el equilibrio se asocia con el incremento de la inflación y de la tasa de interés, por la monetización del déficit o la emisión de grandes volúmenes de bonos gubernamentales sucesivos que afectan principalmente a los pobres y a las pequeñas empresas (Birdsall, 2001). Pero, nuevamente, pensar que cualquier tipo o magnitud de déficit presupuestal elevará la inflación e incrementará la tasa de interés puede ser un error. Dicho déficit presupuestal genera depósitos disponibles en el sistema bancario, conduciendo a la tasa de interés de corto plazo a la baja, y la emisión de bonos drena la cantidad de depósitos adicionales para colocar la tasa en algún punto deseado por la autoridad monetaria. ${ }^{5}$ Pero, aun concediendo sin aceptar que el gasto deficitario tuviera un efecto negativo sobre la tasa de interés, su efecto sobre las pequeñas empresas debe ser valorado en función de la afectación que sufren por la contracción del mercado que, de acuerdo con Keynes, juega un papel preponderante. ${ }^{6}$

Mientras se siga manteniendo una postura económica ortodoxa (de disciplina fiscal) es improbable que se pueda estabilizar la economía real, pues se impide que el gobierno pueda participar en la economía ante el temor inflacionario, situación que, argumentada en términos de la heterodoxia, no resulta cierta por sí misma. Existe la idea, fuertemente arraigada al respecto, de que la inflación y el desempleo son objetivos encontrados, ${ }^{7}$ en los cuales se tiene que mantener una tasa de desempleo "natural" para no generar presiones sobre los precios. Pero como han discutido ampliamente algunos economistas (Lerner, 1957; Wray, 2003; Forstater, 1999; Mitchell, 1998), ello no es cierto en todos los casos y, además, se estima que tener una mano de obra desocupada abundante significa un costo muy alto por mantener estable el nivel de precios (Forstater, 1999), sobre todo en economías donde el

5 El tema del manejo de reservas y su relación con las tasas de interés ha sido ampliamente abordado por economistas de corte poskeynesiano, quienes aseguran que la venta de bonos en una economía moderna no tienen por objeto financiar el gasto de gobierno sino evitar que la tasa de corto plazo caiga a cero (Wray, 2004; Bell, 1998; Mosler y Forstater, 2005).

6 Keynes (2003, 300 301), al referirse a las etapas de auge y al comienzo de las crisis, argumentaba que "la explicación más típica, y con frecuencia la predominante de la crisis, no es principalmente un alza en la tasa de interés, sino un colapso repentino de la eficiencia marginal del capital". La tasa de interés para las empresas tiende a ser relativa, si es alta o baja dependerá del rendimiento de las empresas. Así, en una economía con un mercado interno contraído por políticas fiscales y monetarias restrictivas, una tasa de interés considerada baja puede estar por encima del rendimiento de las empresas, eliminando su posibilidad de acceso al crédito o llevándolas a condiciones de sobreendeudamiento.

7 Seccareccia (2004) menciona que asumir la incompatibilidad entre la inflación y el desempleo es el centro de la perspectiva política neoclásica. 
bienestar de la población se ha deteriorado con el tiempo. Pero de manera adicional se pierde la oportunidad de que el gobierno, mediante una política de gasto dirigida al empleo, pueda estabilizar la economía al establecer a aquel como un estabilizador automático de la política fiscal.

Lo que resta de este documento se compone de los siguientes apartados: en la segunda parte se aborda de manera rápida la relación de la política fiscal y el ciclo económico, para posteriormente describir lo que se entiende como política fiscal contracíclica. A continuación se argumentan las explicaciones dadas sobre la prociclidad de la política fiscal en los países en desarrollo. Después se discute si la disciplina fiscal tiene que anteceder a la postura contracíclica. Por último, se aportan evidencias al respecto de la postura fiscal de México en relación con el ciclo económico. Para concluir, se ofrece una opción para que la política fiscal pueda ser contracíclica.

\section{La política fiscal y el ciclo económico}

Sin intentar ahondar en el tema de los ciclos económicos más allá de lo necesario para establecer su relación con la política fiscal, es importante establecer algunas consideraciones rápidas sobre el ciclo económico.

Para Keynes (2003:299), el ciclo podría ser entendido de la siguiente manera:

al progresar el sistema en dirección ascendente, las fuerzas que lo empujan hacia arriba al principio toman impulso y producen efectos acumulativos unas sobre otras, pero pierden gradualmente su potencia hasta que, en cierto momento, tienden a ser reemplazadas por la operación en sentido opuesto; las cuales, a su vez, toman impulso por cierto tiempo y se fortalecen mutuamente hasta que ellas también, habiendo alcanzado su desarrollo máximo, decaen y dejan su sitio a sus contrarias. ${ }^{8}$

En Keynes, la tendencia ascendente o descendente puede persistir indefinidamente en la misma dirección una vez iniciada, pero en algún momento terminará por reinvertirse, teniendo cierta regularidad en la secuencia de las variaciones. Argumenta que estas últimas se deben a cambios cíclicos en la eficiencia marginal del capital, sin dejar de lado otras variables importantes de periodo corto del sistema económico.

Por su parte, en 1946, Burns y Mitchell ${ }^{9}$ definían al ciclo económico como:

un tipo de fluctuaciones encontradas en la actividad económica agregada de las naciones que organizan su funcionamiento en empresas comerciales. Un ciclo con-

$8 \quad$ En ese sentido, Hansen (1966:16) menciona que "el análisis del ciclo tiende a reforzar la opinión de que una vez que un movimiento ha comenzado en una dirección, tiende a acumularse y fortalecerse hasta un punto determinado más allá del cual las fuerzas generadoras se debilitan hasta que se inicia un movimiento en dirección opuesta".

9 Citados por Diebold y Rudebusch (1996). 
siste en expansiones que ocurren aproximadamente al mismo tiempo en muchas actividades económicas, seguidas generalmente de recesiones, contracciones y reactivaciones que se conectan con la fase de expansión del ciclo siguiente.

En el largo plazo se asume que la economía crece a un ritmo tendencial, que puede estar sujeta a cambios de corto plazo en los cuales se puede estar por arriba o por debajo de la tendencia. La interpretación que hace Kalecki (1984:19-24) sobre el ciclo económico se relaciona con la demanda por bienes de inversión, cuando se incrementan los pedidos por éstos se da un incremento en la actividad inversora, hasta el momento en que la demanda de inversión supera el nivel de necesidades de reposición, originando una disminución en dichos pedidos. Kalecki divide el ciclo económico en cuatro etapas: recuperación, auge, recesión y depresión. ${ }^{10}$

En la fase de recuperación se asume que los pedidos de bienes de inversión superan el nivel de las necesidades de reposición sin que el equipo de capital se haya expandido aún; en el auge las entregas de nuevo equipo superan las necesidades de reposición y como consecuencia, el equipo de capital empieza a expandirse ${ }^{11}$ (en esta etapa comienza una disminución en los pedidos y posteriormente su caída); en la recesión los pedidos de bienes de inversión están por debajo de las necesidades de reposición, pero el equipo de capital sigue creciendo por el retraso en las entregas; por último, en la depresión, las entregas de nuevo equipo están por debajo del nivel de las necesidades de reposición y con ello se reduce el volumen de equipo de capital, que en algún momento incidirá en un nuevo incremento en los pedidos de bienes de capital, comenzando nuevamente el ciclo.

Continuando a Kalecki (1984:43), el componente de auge para una economía consiste en la creación de "poder adquisitivo adicional", que tendrá la gran virtud de poner en movimiento el mecanismo a la alza, papel que puede jugar el gobierno. Cuando éste emite bonos y son colocados en el sistema bancario, los bancos recurren a sus reservas para comprar la emisión; una vez que aquel comienza a invertir en infraestructura, genera dos tipos de efecto: en la industria de los bienes de inversión y también en la de bienes de consumo. La cantidad adicional introducida a la economía por el gobierno llega a los capitalistas como beneficios y regresa a los bancos como depósitos listos para adquirir la nueva emisión de bonos que seguirán financiando el gasto en infraestructura pública. Para que esta estrategia de auge pueda tener éxito, es absolutamente necesario que se propicie la creación de nuevo

10 Dornbusch y Fischer (1994:16), enuncian las etapas del ciclo como: recuperación, cima, recesión y fondo.

11 Parafraseando a Kalecki (1984:42), la expansión del equipo pone fin al auge e inicia la fase a la baja, mientras que su contracción es el germen de la fase al alza, entre otras cosas por el incremento en el grado de utilización que tienen las unidades económicas que siguen satisfaciendo la misma cantidad de demanda. 
poder adquisitivo, y para ello es indispensable que el banco central adopte una política acomodaticia que no incida en el incremento de la tasa de interés hasta algún nivel en que pueda desincentivar la inversión de los agentes privados; si esto sucede tan sólo se estará dando un crowding-out.

El gobierno, mediante el manejo de una política de gasto deficitario, puede conducir una estrategia de auge destinando recursos para la formación de capital humano o, bien, como se propone en las conclusiones, llevando a cabo un programa público de empleo que permitiría que la política fuera contracíclica, sin dejar de mencionar que ésta, de manera automática, debería de serlo. ${ }^{12}$ Sin embargo, no ocurre así como se verá a continuación, no sin antes especificar qué se entiende por una política fiscal contracíclica.

\section{Política fiscal contracíclica}

Una postura fiscal contracíclica debería conllevar la ejecución de un déficit fiscal considerable cuando las condiciones económicas son malas, y déficit fiscal pequeño o superávit en tiempos de bonanza. Pero el comportamiento del presupuesto fiscal puede estar determinado por dos causas diferentes: el reflejo del entorno económico o, bien, el resultado de decisiones políticas discrecionales:

Sistemáticamente, uno puede pensar que cambios en las variables fiscales son la suma de dos componentes: El primero refleja el ajuste automático de las variables fiscales al ambiente económico subyacente; mientras que el segundo son los cambios discrecionales implementados por los responsables de la política fiscal (Gavin y Perotti, 1997).

Ante una postura de política fiscal discrecional que se mantiene acíclica, el entorno económico conduciría al presupuesto fiscal a un comportamiento contracíclico, es decir, se incrementaría el déficit en recesión y disminuiría conforme se recuperara la economía: "Si se mantiene la tasa impositiva y el gasto público discrecional constantes durante el ciclo económico, deberá de observarse un comportamiento contracíclico de la política fiscal" (Alesina y Tabellini, 2005).

12 Mediante el uso de estabilizadores automáticos, por los cuales se entiende cualquier elemento presupuestal que compensa las fluctuaciones de la demanda ya sea con ingresos o gastos del gobierno, sin que se requiera un proceso legislativo para su aprobación. Para Auerbach y Feenberg (2000), éstos deben incluso operar sin que ello implique una acción explícita del gobierno. Ejemplos pueden ser: por el lado de los ingresos, los impuestos sobre la renta -que regulan la cantidad de gasto privado-, mientras que por el lado del gasto pueden contabilizarse los programas de desempleo y seguridad social. Para ampliar la discusión al respecto de los estabilizadores automáticos, pueden revisarse los casos de Nueva Zelanda y Estonia en Tam y Kirkham (2001) y Kattai et al. (2003), así como Cohen y Follette (2000). 
Por el lado de los tributos, en una postura fiscal acíclica, los impuestos tienden a disminuir cuando se reduce el ingreso nacional, ${ }^{13}$ si la disminución de los ingresos por impuestos ocurre, se podría argumentar que la política fiscal es contracíclica. Pero a decir de Emre y Kuman (2005), los ingresos tributarios ofrecen mensajes ambiguos, ya que como proporción del PIB pueden incrementarse, decrecer o permanecer constantes, dependiendo de la magnitud de la variación del PIB. Otro problema de los ingresos tributarios que sirven como indicador cíclico consiste en su forma de integración; éstos pueden incrementarse por un aumento en la tasa en la base o, incluso, cuando se den disminuciones en la tasa, se puede registrar mayor ingreso como resultado de la ampliación de la base. ${ }^{14}$

Mientras que por el lado del gasto, una postura política acíclica debería verse como un incremento en la proporción del gasto respecto del PIB bajo un declive en el nivel de actividad económica; si los gastos se mantienen constantes, la parte proporcional de éstos respecto del PIB se incrementarán. Es probable que cuando la debilidad de la economía se prolongue el gasto del gobierno no permanezca constante y tienda a incrementarse por diversas presiones sociales. La postura de política contracíclica va más allá de tan sólo solventar las apremiantes necesidades sociales, ya que ésta buscará por varios medios de aplicación del gasto público incrementar la rentabilidad de los agentes privados para que su actividad siga siendo rentable.

En resumen y desde el planteamiento keynesiano, la política fiscal, al tener una postura contracíclica, propiamente lo que hace es regular la cantidad de demanda agregada en la economía y, en ese sentido, a diferencia de la visión neoclásica, es completamente válido que el gobierno participe tanto como sea necesario (Budnevich, 2002). Siempre que la economía se encuentre en el pleno empleo, el gobierno deberá ejecutar superávit, mientras que el déficit se hace necesario en la recesión. Desde esa perspectiva y dado que el pleno empleo en el mejor de los casos es una construcción hipotética del mainstream, se puede argumentar, como lo hace Wray (1999 y 2002), que mantener déficit presupuestal es el estado normal de cualquier economía capitalista.

13 Como resultado de una menor actividad económica.

14 Braconier y Forsfält (2004), considerando ese inconveniente, mencionan que los ingresos por concepto de impuestos dependen de tres variables: la tasa implícita del impuesto, la base como proporción del PIB y el PIB.

$$
\mathrm{T}_{\mathrm{i}}=\left(\mathrm{T}_{\mathrm{i}} / \mathrm{B}_{\mathrm{i}}\right)^{*}\left(\mathrm{~B}_{\mathrm{i}} / \mathrm{Y}\right)^{*} \mathrm{Y}
$$

en la cual: $\mathrm{T}_{\mathrm{i}}=$ es el ingreso por cierto impuesto. $\left(\mathrm{T}_{\mathrm{i}} / \mathrm{B}_{\mathrm{i}}\right)=$ Tasa implícita del impuesto. $\left(\mathrm{B}_{\mathrm{i}} /\right.$ Y) = La base del impuesto como proporción del PIB. Y = PIB. Los ingresos se modificarán como resultado en un cambio en alguno de los tres componentes del lado derecho de la ecuación y dicho cambio puede ser considerado de política. 
Una política fiscal procíclica, por tanto, es opuesta a lo mencionado anteriormente, disminuye el gasto e incrementa recaudación en los malos tiempos y viceversa en los buenos. La pregunta es: ¿por qué ocurre esto?, y ¿por qué principalmente lo resienten economías en vías de desarrollo?

\section{Causas de la prociclidad de la politica fiscal}

Como se había comentado, en los países desarrollados la política fiscal ha presentado un comportamiento contracíclico, a diferencia de lo que ocurre en los países en desarrollo. Parte de la discusión se plasma a continuación.

\section{Los flujos de capital}

Una de las principales causas que se encuentran presentes en la explicación que se hace de la postura procíclica de la política fiscal, es su relación con la volatilidad de la producción agregada. A medida que los países incrementan la volatilidad de su producto tienden a tener una postura fiscal procíclica. Para Emre y Kumar (2005), la exposición de los países al comercio exterior puede ser una variable proxy para la volatilidad del producto, pero su relación es mayor con el ciclo de los flujos de capital, que es altamente procíclico.

Muchos economistas (Stiglitz, 2003) han documentado que los mercados de capital conllevan un comportamiento procíclico en los países en desarrollo, ya que, al igual que los impuestos, los flujos de entrada disminuyen en tiempos de baja actividad, exacerbando así la contracción económica. Pero no sólo eso, ante la posibilidad de incumplimiento, los flujos de salida de capital tienden a incrementarse, con lo cual se dará una contracción del gasto de gobierno o, bien, un incremento de los impuestos con la finalidad de pagar la deuda contraída en los periodos ascendentes del ciclo, cuando los flujos de ingreso de capital llegaron a los países en busca de los rendimientos que pudieran generarse.

Para Gavin y Perotti (1997), la restricción de las líneas de crédito ayudan a comprender la incapacidad de los gobiernos para mantener una postura contracíclica en periodos de disminución del ingreso nacional:

En Latinoamérica, los responsables de las políticas fiscales típicamente han encarado una pérdida de confianza que ha incrementado su restricción para la obtención de préstamos durante los malos tiempos. La pérdida del acceso a los mercados hace imposible que puedan ejecutar política fiscal contracíclica, al menos en los malos tiempos [...] La idea que la restricción en la obtención de préstamos tiende a ser reforzada en los malos tiempos aporta una explicación del porqué la política fiscal es particularmente procíclica durante tales tiempos; las autoridades desean implementar más política fiscal contracíclica, pero están imposibilitadas de hacerlo por su incapacidad para financiar el déficit fiscal que ello implica. 
Los autores argumentan que la restricción al crédito más la incapacidad de acceso a financiamiento no inflacionario ayuda a explicar el porqué el déficit es menos persistente en América Latina que en países desarrollados.

Así, la postura procíclica de los flujos de capital configura la postura procíclica de la política fiscal, en otras palabras, se puede decir que la disponibilidad del dinero de acuerdo con el momento del ciclo económico es una variable importante para determinar la relación de la política fiscal con el ciclo económico. La abundancia de capital lleva a los países en desarrollo a trabajar con déficit presupuestal en tiempos de auge, que los limita en tiempos de recesión cuando hay que pagar la factura.

Aun cuando la explicación y el comportamiento de la economía pudieran estar debidamente respaldados por la restricción que impone la menor entrada de flujos de capital al país, el problema consiste en la autoflagelación del gobierno respecto de sus propias restricciones para financiar su gasto. La limitación financiera real de un gobierno, de acuerdo con Wray (2000), consiste en el empeño de los gobiernos por mantener un tipo de cambio fijo, que limita su margen de maniobra para utilizar su verdadera capacidad de financiamiento. Pero incluso la emisión de dinero de alta potencia, potestad que los estados nacionales modernos declinaron, no tendría necesariamente que ser inflacionario, todo depende del uso que se le dé a los recursos. ${ }^{15}$

\section{El papel del gasto}

A decir de algunos autores de países latinoamericanos, el gasto público ha jugado un papel procíclico al manejar políticas de subsidio y empleo en momentos en que la economía está creciendo por su propia dinámica. La explicación que se da al respecto es que ante la abundancia de recursos los grupos al mando de la dirección y toma de decisiones están interesados en conservar su coto de poder y, por lo tanto, instrumentan medidas de corte populista con el afán de mantener la aceptación de los votantes. A medida que las condiciones en un país mejoran, los votantes exigen impuestos menores y mejores servicios públicos, con lo cual se incrementa el gasto de gobierno durante los tiempos de prosperidad y se cae en un excesivo endeudamiento que limitará el gasto en la recesión. Las demandas de los votantes y la miopía de la política fiscal, a decir de Alesina y Tabellini (2005), constituyen un medio que conduce a la prociclidad de la política fiscal, que en la mayoría de los casos se da por el lado del gasto, pero que no necesariamente son los elementos

15 Para el caso específico de México, Romero (1999) explicaba una modalidad en la cual la emisión primaria de circulante no tendría que estar asociada a la generación de inflación. 
principales, para ellos la corrupción que impera en los países en desarrollo se configura como el principal factor, aun por encima de la restricción crediticia:

Los votantes encaran gobiernos corruptos que pueden apropiarse parte de los ingresos tributarios para consumo público improductivo, por ejemplo, rentas políticas. Las rentas pueden ser a través de apropiación directa (robo) de ingresos tributarios por parte de funcionarios públicos o bien por el pago de favores por intereses especiales, tales como el empleo de amigos del gobierno identificados frecuentemente entre etnias, líneas religiosas, etcétera.

Las presiones políticas para incrementar el gasto de gobierno en momentos de auge, de acuerdo con Talvi y Végh (2000), impiden que el gobierno pueda acumular superávit fiscal que se asume necesario para poder llevar a cabo una política contracíclica. En ese sentido, se piensa que el gobierno debería reducir las tasas impositivas para aminorar sus ingresos y con ello contener el sobregasto derivado de las presiones políticas (Braun y Di Gresia, 2003). De acuerdo con esa percepción, si se controlan los ingresos a la baja, se puede controlar el gasto, con la intensión de generar suficiente ahorro y utilizarlo en los tiempos malos. En esencia, el argumento intenta regular la política fiscal para evitar las presiones políticas y, sobre todo, permitir que en tiempos difíciles se pueda ampliar el gasto sin que se tengan limitaciones por la carencia de créditos.

El punto por discutir consistiría en establecer la necesidad de que el gobierno genere ahorros para estar en condiciones de ampliar su gasto, y sí, ésa es una condición necesaria para que lo pueda hacer, como se discute a continuación.

\section{¿La disciplina fiscal tiene que anteceder al uso de la política contracíclica?}

De acuerdo con Willianson (2004b), el uso de una política fiscal dirigida a disminuir las fluctuaciones económicas cíclicas debe ser iniciada en los periodos de auge económico. En los tiempos buenos la política fiscal debe ser mesurada y, en ese sentido, debe mantenerse una estricta disciplina fiscal que le permita al gobierno mantener su habilidad de intervenir en eventos o sucesos adversos. En esta misma línea, Budnevich (2002) pone como condición para la postura fiscal contracíclica dos aspectos: que las cuentas fiscales deben ser solventes y sustentables, además de una reingeniería de las instituciones correspondientes que incremente la oportunidad y flexibilidad de la política fiscal.

En el contexto actual se podría pensar en la necesidad de que el Estado ahorre en tiempos de auge para estar en condiciones de gastar en momentos de recesión, pero ello sería como pensar que el Estado es similar a una empresa o a los individuos, cuando el símil es de suyo erróneo. El Estado tiene facultades que no son inherentes 
a los individuos ni a las empresas, ${ }^{16}$ tales como: su capacidad de imponer contribuciones, el poder de declarar la aceptación pública, el poder de crear y destruir dinero y la capacidad de comprar y vender deuda y, en ese sentido, su capacidad para realizar pagos monetarios no debe ser restricta, ${ }^{17}$ por lo tanto, no necesita nunca reunir superávit en algún momento para realizar pagos monetarios en el futuro (Bell y Wray, 2000).

Si el gobierno empieza a generar ahorros, es decir, a gastar menos de lo que recauda por concepto de impuesto, está generando superávit presupuestal. Pero para lograrlo, lo que hace es disminuir la riqueza nominal del sector no gubernamental, o sea, cuando el gobierno retira más obligaciones de las que coloca en el mercado lo hace al reducir de sus obligaciones en propiedad de los agentes privados bajando sus tenencias. El conflicto que se da es que la generación del superávit presupuestal no se ahorra para el futuro ni puede ser usado para financiar mayor gasto o la disminución de los impuestos; un superávit existe sólo como una reducción del ingreso del sector privado, ${ }^{18}$ el superávit reduce los ahorros del mismo y no puede hacerlo para el futuro y, lo que es más, no puede ser duradero: una economía no puede crecer permanentemente mientras el gobierno extrae el ingreso disponible y la riqueza del sector privado, cuando la economía empieza a tener menos impuestos y la demanda por mayor gasto social pondrán de manifiesto la incapacidad de sostenerlo (Wray, 2002).

16 Sawyer (1997) describe al menos tres elementos de distinción entre el gobierno y los individuos: en principio, mientras los individuos actúan en su propio beneficio, el gobierno actúa de acuerdo con el interés del grueso de la sociedad, cuando el gobierno ejecuta déficit o superávit presupuestal lo hace pensando en el impacto sobre la economía, además de que por su tamaño, a diferencia de algunas organizaciones, sus decisiones sí tienen impacto sobre la macroeconomía; el gobierno puede obtener préstamos a menores tasas de interés que los individuos, facultad que le deviene de su capacidad para respaldarlos con la imposición tributaria; el gobierno puede endeudarse continuamente sin que ello pueda ocasionar una posición de endeudamiento siempre y cuando su tasa de crecimiento sea mayor a la tasa de interés real pagada por el servicio de su deuda, condición que aplica a los individuos, con la diferencia de que ellos no pueden incidir en la tasa de interés; y, por último, el grueso de los bienes y servicios que proporciona el gobierno son de los denominados de no-mercado, por lo cual no recibe ingresos directos, aun cuando de forma indirecta recibe impuestos.

17 A decir de Mosler y Forstater (2004), la distinción clave entre el gobierno y el sector no gubernamental estriba en el hecho de que el primero es el emisor de la moneda, mientras que el segundo tan sólo es usuario de la misma. Operacionalmente, el gasto público consiste en abonar en la cuenta de un banco miembro del banco central o pagando en efectivo. Por lo tanto, a diferencia de los usuarios de la moneda, y en dirección opuesta a la concepción popular, el emisor de la moneda no debería restringir su gasto a sus ingresos.

18 Wray (1999) menciona que en este sentido debería ser abolida la palabra de superávit, y que cuando nos estuviéramos refiriendo a la situación en la que el ingreso tributario excede el gasto lo hagamos de la siguiente manera "government's net drain on private sector income", o mejor aún, el "great sucking sound as private wealth is destroyed by government". 
EDUARDO RAMÍREZ CEDILLO

94

Cuadro 1

Balance externo, público y privado

\begin{tabular}{lcccccc}
\hline & 1999 & 2000 & 2001 & 2002 & 2003 & 2004 \\
\hline Balance comercial & $-0.9 \%$ & $-2.5 \%$ & $-3.3 \%$ & $-3.2 \%$ & $-2.5 \%$ & $-2.3 \%$ \\
Déficit público & $1.10 \%$ & $1.10 \%$ & $0.70 \%$ & $1.10 \%$ & $0.60 \%$ & $0.20 \%$ \\
Balance del sector privado & $0.2 \%$ & $-1.4 \%$ & $-2.6 \%$ & $-2.1 \%$ & $-1.9 \%$ & $-2.1 \%$ \\
\hline
\end{tabular}

Fuente: elaboración propia con datos del BANXICO y la SHCP.

En México, incluso cuando se han realizado serios esfuerzos por lograr superávit en el sector público, no se ha llegado a esa situación, pero hubo repetidos anuncios por parte de la Presidencia de la República que en 2006 se estaría en condiciones de ejercer un superávit del sector público de alrededor de $0.2 \%$ del PIB. Con lo cual, después del desarrollo anterior, se pensaría en un deterioro del ahorro del sector privado, que a decir verdad no empezará en 2006, en el mejor de los casos se ha venido arrastrando desde 2000 (Cuadro 1), en virtud de que el déficit de comercio exterior tiene un efecto similar al del superávit presupuestal para los agentes privados, cuando éste no es compensado por el déficit presupuestal.

Si se toma a la economía en su conjunto, cuando un sector gasta más de lo que genera por sus ingresos, otro sector tendrá que gastar menos, razón por la cual en el agregado la suma del total de ingresos es igual a la totalidad del gasto. Partiendo de la ecuación de ganancias propuesta por Kalecki:

$$
(S-I)=(G-T)+(X-M)
$$

Y de acuerdo con Wray (2002), resulta claro que si el gobierno gasta menos de su ingreso (manteniendo el sector externo en equilibrio) el sector privado gastará más, incurriendo en déficit. No obstante que el déficit del sector público es pequeño, el sector privado es deficitario por lo que se tiene en el sector externo y solamente podrá dejar de serlo con dos alternativas: un incremento del déficit presupuestal que compense el comportamiento negativo del sector externo o bien una disminución del déficit exterior. La disminución del déficit de comercio exterior se torna sumamente complicada por las condiciones de apertura comercial y financiera a las que se enfrenta el país, mientras que el incremento del déficit no se consolidaría de seguirse manteniendo la estabilidad cambiaria, ya que ésta exige trabajar con disciplina fiscal, como se había comentado en líneas anteriores.

El argumento sobre el que descansaba la explicación de que un incremento en el déficit presupuestal incidiría en mayor importación de bienes y, por lo tanto, en mayor déficit comercial no es aplicable para la economía de México, al menos para 
los últimos seis años (Cuadro 1), en los cuales el déficit comercial ha tenido su propia dinámica. Pero la disciplina fiscal sí ha presionado al sector externo, el mecanismo de transmisión se da porque esta política manda señales de menor presión sobre los precios que al ir acompañada de la expectativa de un nuevo proceso de privatización, contribuye a la entrada de capitales que aprecia el tipo de cambio y permite un incremento en las importaciones mayor al de las exportaciones. ${ }^{19} \mathrm{La}$ disminución del gasto para lograr la disciplina fiscal también incide en la esfera productiva, lo cual incrementa los rezagos del sector, beneficiando nuevamente el incremento de las importaciones (Huerta, 2004b).

Es justo mencionar que en una economía abierta se debe tener una política de gasto deficitario cuidadosamente planeada para evitar que se fuguen los efectos multiplicadores al exterior, de lo contrario el argumento vertido en el párrafo anterior no tendrá validez. ${ }^{20}$

\section{México, el ciclo económico y su respuesta fiscal}

En México, el ciclo económico no es amortiguado por la política fiscal, ya que ésta responde de manera procíclica, como se apunta en el Apéndice. Tomando cuatro variables fiscales, dos de ingreso y dos de gasto, que corresponden a los ingresos totales y tributarios, por una parte, y a los gastos totales y de no pago de intereses, por otra, en un periodo que va de 1980 a 2004, se comprobó que tres de las cuatro variables han tenido un comportamiento procíclico.

En el caso del ingreso, no es una sorpresa que su comportamiento, como se ha dicho, tienda a ser más procíclico que contracíclico o que en algunos casos no juegue un papel relevante. La explicación que puede argumentarse para la prociclidad del gasto es la carencia de programas de desempleo y de protección social que impiden generar mecanismos de estabilización automática (Mohanty y Scatigna, 2003). Para solventar esta situación, en el siguiente apartado, a manera de propuesta, se menciona como una alternativa, para lograr una política fiscal contracíclica, la instauración de un programa público de empleo.

El argumento de la falta de gasto social como elemento que incide en la postura fiscal puede ser coherente en el caso de México, ya que durante los últimos años se

19 Situación similar a lo ocurrido a inicios de la década de los noventa.

20 Abundando un poco más en el comentario, se sabe que en una economía abierta la ampliación de la demanda agregada puede tener una repercusión importante en la cantidad de bienes de importación. La clave a este respecto radica en que la ampliación de la demanda sea dirigida a aquellos sectores con un alto componente nacional para que los efectos multiplicadores resultantes se queden en el país. Si ello sucede, no se tendría que temer que una ampliación en la demanda agregada originada por un aumento en el gasto de gobierno resulte en la ampliación del déficit comercial. 
ha incrementado el gasto social y la postura fiscal ha pasado de ser altamente procíclica (0.78 en el periodo de 1995 a 1999) a una acíclica (0.06 en el periodo de 2000 a 2004, como se puede observar en el Cuadro 1 del Apéndice) en lo concerniente al gasto de no-pago de intereses. Desde luego que el resultado aún es poco satisfactorio y lo es en esencia por el deseo, a toda costa, de mantener en equilibrio las finanzas públicas. ${ }^{21}$

\section{A manera de conclusión y propuesta}

Se tiene evidencia para constatar la procíclidad de la política fiscal, misma que ha llevado al deterioro de las condiciones de bienestar del país al no poder mantener un ritmo de crecimiento sostenido, que se ve continuamente sometido a altibajos que tienen un costo importante para la sociedad, al disminuir la cantidad de empleos formales y, con ello, la oportunidad de contar con servicios de seguridad social. Ante tal eventualidad, se esperaría que las demandas sociales obligaran a un gasto público mayor que rompiera con la disciplina fiscal, sin que hasta el momento se haya dado, no por que no se incremente el gasto social, sino por que el mismo es objeto de una disminución en otros sectores que también son importantes.

El mantenimiento de la estabilidad monetaria que facilita la entrada de capitales, impide que la política fiscal tenga margen de maniobra para trabajar de forma contracíclica, porque ante la señal del uso de gasto deficitario los inversionistas extranjeros advierten peligros de no cumplimiento que obligarían al gobierno a ofrecer tasas de interés mayores para mantener los flujos de capital o, bien, ofrecer oportunidades de inversión en sectores productivos altamente rentables para que sigan llegando, y los que ya se encuentran en el país no salgan. El uso de políticas restrictivas para lograr la entrada de capitales juega en contra de los sectores productivos privados al generar el incremento de la tasa de interés y la apreciación del tipo de cambio que atentan contra la productividad y competitividad del sector, en detrimento del empleo y, por ende, del propio crecimiento económico. ${ }^{22}$

Una posible alternativa para incentivar una postura contracíclica de la política fiscal puede ser la instrumentación de un programa público de empleo, ya que éste

21 En los periodos referidos de 1995 1999 y 2000 2004, el gasto en desarrollo social fue, en promedio, de 8.73 y $9.98 \%$ en relación con el PIB, respectivamente, el problema consiste en que éste no es un incremento neto, es decir, se disminuye la participación en otros rubros para que pueda ser incrementado el gasto en desarrollo social, como se puede constatar revisando las cifras del gasto asignado a actividades productivas, que fue en promedio de 5.36 y $4.84 \%$ del PIB, respectivamente.

22 En materia de competitividad en el nivel global, el país ha caído de la posición 31 a la 55 de 1999 a 2005, de acuerdo con "The Global Competitiveness Report", presentado por "The World Economic Forum". 
puede servir como estabilizador automático. La generación de empleos podría actuar desde los dos lados de la moneda incentivando el gasto y subvencionando el ingreso. En el primer caso, el gobierno, mediante un programa público ad hoc puede generar empleos por su propia cuenta o bien podría estimular a los agentes privados mediante mecanismos fiscales para que éstos estén en condiciones de generar una parte de esos espacios. En los dos casos se cumple el objetivo, pero el mecanismo más confiable para la creación de éstos será el gasto de gobierno. ${ }^{23}$

El programa público de empleo por parte del gobierno no debe tener la expectativa de crear empleos permanentes, los empleos generados deben tener carácter temporal, siendo la reactivación económica la que determine la duración de los mismos. ${ }^{24}$ La movilidad de la fuerza laboral se irá dando mediante la búsqueda de mejores salarios en comparación con los que pague el gobierno, así las empresas, ante mayores expectativas de realización de sus bienes y servicios en el mercado, estarán en condiciones de ofrecer empleos con mejores salarios a los ofrecidos por el sector público y con ello se dará una disminución de trabajadores al servicio del Estado.

La lógica en la que se sustenta la suposición de la movilidad de los trabajadores del sector público al privado consiste en el establecimiento de un salario mínimo para las personas que sean objeto del programa público de empleo. ${ }^{25}$ La propuesta tiene la ventaja de que la movilidad de los trabajadores se daría del sector público al privado en lugar de darse del desempleo al empleo o incluso de la informalidad a la formalidad.

Aún cuando ya existe un Programa de Empleo Temporal (PET), ${ }^{26}$ operado por el gobierno federal, la diferencia estriba en que la propuesta no tiene una población objetivo ni una duración específica en la contratación de la mano de obra, la única salvedad consiste en que las actividades sean altamente rentables para las comunidades, la sociedad y el país y su duración estará dada por la recuperación económica, como se comentó. Es importante mencionar que el financiamiento de tal programa

23 Una valoración respecto de tres propuestas para disminuir el desempleo consisten en: a) el incremento de la inversión pública para alentar la inversión privada, $b$ ) la disminución de la tasa de interés para incentivar la inversión privada, y c) el incremento de incentivos de trabajar de empresas y trabajadores. Bell (2000) concluye que la opción de la creación directa de empleos por parte del gobierno es quizá la mejor, por los efectos que ésta tendrá en el incremento de la demanda del mercado y, con ello, de las expectativas del sector privado.

24 Forstater (2005) menciona que un programa público de empleo actúa como un fuerte estabilizador automático, en virtud de que el déficit crece cuando la economía se contrae y diminuye cuando la economía se expande.

25 La función de los salarios es inducir a los trabajadores a laborar y hacerles realizar la clase de trabajo que mejor satisfaga las necesidades de los consumidores. Ofrecer salarios más altos es el medio de atraer a los trabajadores a donde más se les necesita, asimismo, ofrecer salarios más bajos es el medio de persuadirlos para que se vayan de donde menos se les necesita (Lerner, 1957:184).

26 El PET está dirigido a la población rural en pobreza extrema mayor de 16 años que este dispuesta a participar en el mismo, pudiendo ser productores rurales, jornaleros con y sin 
no debería estar sujeto a la disciplina fiscal en la medida en la cual se pretende que funcione como un estabilizador automático, en contrapartida con lo que ocurre con el PET, que se comporta seriamente restrictivo con el equilibrio presupuestal.

Lamentablemente, por razones de espacio no se aborda a profundidad las características del programa, pero un desarrollo más acabado del mismo puede ser revisado en Ramírez (2006), no obstante se puede mencionar que un programa público de empleo, cualesquiera que sean sus características, debe ser permanente (no así la cantidad de empleos que se generen), cambiando la intensidad del mismo de acuerdo con el ciclo económico, por lo que se podría argumentar, sin problema alguno, que en ese sentido el programa se puede visualizar como contracíclico, es decir, que en los momentos de recesión económica deberá ser más intenso y a medida que la economía incremente su crecimiento la intensidad de los recursos dedicados al programa tendrán que disminuir.

Si bien la instrumentación del programa puede implicar el incremento del déficit (que como se había anotado, la incursión en éste es parte de una política fiscal contracíclica), esto debe ser valorado tan sólo como un medio para alcanzar un fin. Teniendo en cuenta que si el déficit tiene la intensión de acabar con el desempleo de manera directa, siempre se tendrá una buena referencia para valorar hasta dónde el déficit puede resultar excesivo. Es decir, en que punto, de acuerdo con el desempleo, se tiene que dejar de crear vacantes laborales e inyectar recursos deficitarios.

La incursión del gobierno en un programa público de empleos resultaría sustentable para las finanzas públicas, ya que al incrementarse la actividad económica ante la ampliación del déficit gubernamental se incrementaría la demanda agregada y se generarían nuevas oportunidades de inversión con un mercado interno mayor, generando una captación tributaria más elevada. Asimismo, la implantación del programa, aun cuando se hiciera con cargo adicional al déficit presupuestal, no incidiría en mayores niveles de endeudamiento si se mantuviera una tasa de interés real, con la participación de la política monetaria, por debajo de la tasa de crecimiento (Arestis y Sawyer, 2003), en la cual los ingresos del gobierno deberían de crecer a un ritmo mayor que el servicio de la deuda que se genere como resultado de las erogaciones deficitarias para financiar el programa.

Para concluir, México es capaz de establecer un programa público de empleo y con ello ejecutar una política fiscal de postura contracíclica si logra disminuir su requerimiento de divisas que lo obligan a trabajar con un tipo de cambio fijo. ${ }^{27}$ Para ello, debería de renegociar la deuda externa, regular los flujos de capitales y revisar

tierra, y hombres y mujeres que habiten las áreas rurales de ciertas regiones, dicho progra ma tiene una duración máxima de 88 jornales.

27 Al hablar de un tipo de cambio fijo, se hace referencia a un tipo de cambio determinado por la participación o intervención del Banco Central. El tipo de cambio no es fijo en el estricto 
su apertura comercial para estar en condiciones de dejar flotar su moneda y retomar su política económica soberana. ${ }^{28} \mathrm{Si}$ ello se consigue, la economía podrá disminuir sus fluctuaciones y mantener periodos de crecimiento sostenido, mismos que en los últimos años han estado ausentes.

\section{Apéndice}

Se pretende establecer el ciclo económico de México y su relación con la postura fiscal. Por tal motivo se requiere separar de los datos del producto la tendencia del ciclo. Un método para realizar esta operación consiste en la utilización del filtro de Hodrick y Prescott (1997). ${ }^{29}$

El filtro de Hodrick y Prescott consiste en minimizar la variación de una serie y alrededor de su tendencia $s$, sujeta a una penalización que restringe las segundas diferencias de $s$.

La elección del coeficiente de penalización $\lambda$, de acuerdo con Hodrick y Prescott, depende de la periodicidad de la información; para datos trimestrales, como los usados en este caso, se aconseja que el coeficiente sea de 1600.

$$
\sum_{t=1}^{T}\left(y_{t}-s_{t}\right)^{2}+\lambda \sum_{t=2}^{T-1}\left(\left(s_{t+1}-s_{t}\right)-\left(s_{t}-s_{t-1}\right)\right)^{2}
$$

Se inicia el trabajo con la serie del PIB para el periodo de 1980 a 2004, usando datos trimestrales desestacionalizados. Para la desestacionalización de la serie se usó el método de promedios móviles, que consiste en lo siguiente:

Se calcula el promedio móvil de la variable $y_{t}$ como:

$$
x_{t}=\left(0.5 y_{t+2}-y_{t+1}-y_{t}-y_{t-1}-0.5 y_{t-1}\right) / 4
$$

Tomando el cociente $t_{t}=y_{t} / x_{t}$. Una vez que se tiene el cociente se calcula el índice estacional $s$ y se desestacionaliza la serie.

$$
s=i_{q} /\left(\sqrt[4]{i_{1} i_{2} i_{3} i_{4}}\right)
$$

sentido de mantener una paridad sin cambios, no obstante, el mismo no está determinado por el poder de la paridad de compra (PPP). En este sentido el concepto tipo de cambio fijo no hace alusión al mantenido por México durante 22 años y que tuvo su fin en 1976.

28 El manejo de política económica soberana por parte del Estado es un punto de suma importancia si se considera necesaria la ejecución de déficit presupuestal para la estabilización del ciclo económico. Por tal motivo, su mención obliga la realización de futuras investigaciones en las cuales el punto sea tratado de manera central.

29 Millar (2003) clasifica los diferentes métodos para estimar el pIB potencial, que es la tendencia del PIB real, en cuatro: métodos directos, métodos no estructurados y métodos multivariados. El método utilizado en este documento es del tipo no estructurado. 
En la Gráfica 1 se puede observar el comportamiento del PIB real desestacionalizado (línea continua), además de la tendencia (línea punteada). En la Gráfica 2 se presenta la parte cíclica de la serie, que es la diferencia entre el valor de la serie en un punto y el valor de la tendencia en ese punto.

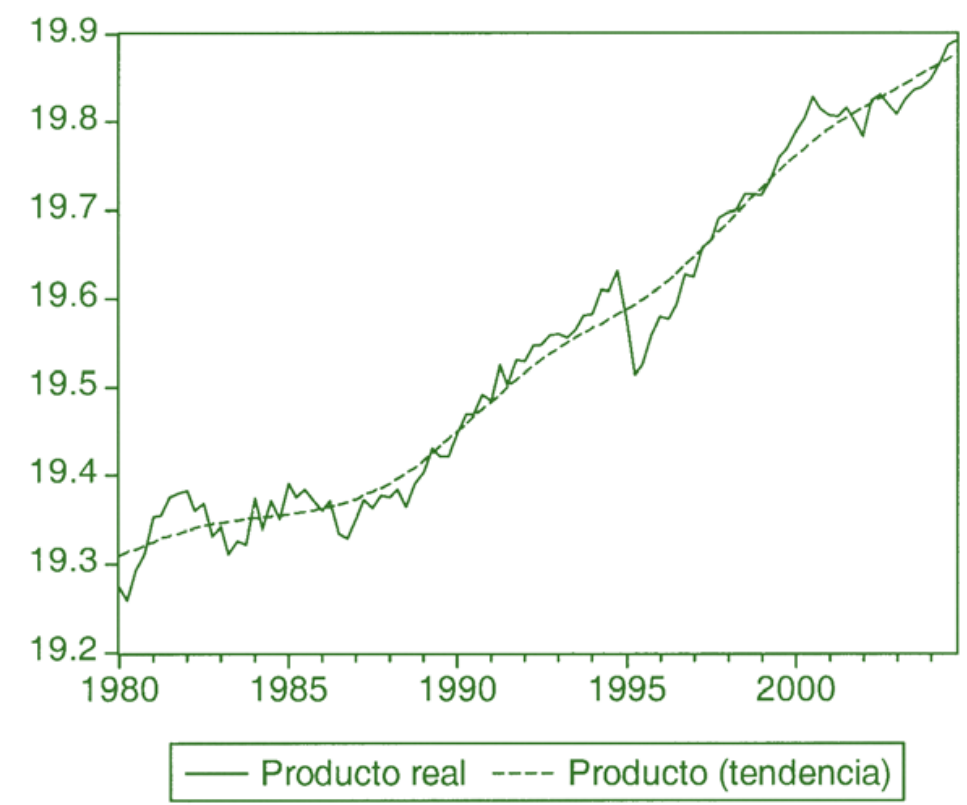

Gráfica 1.

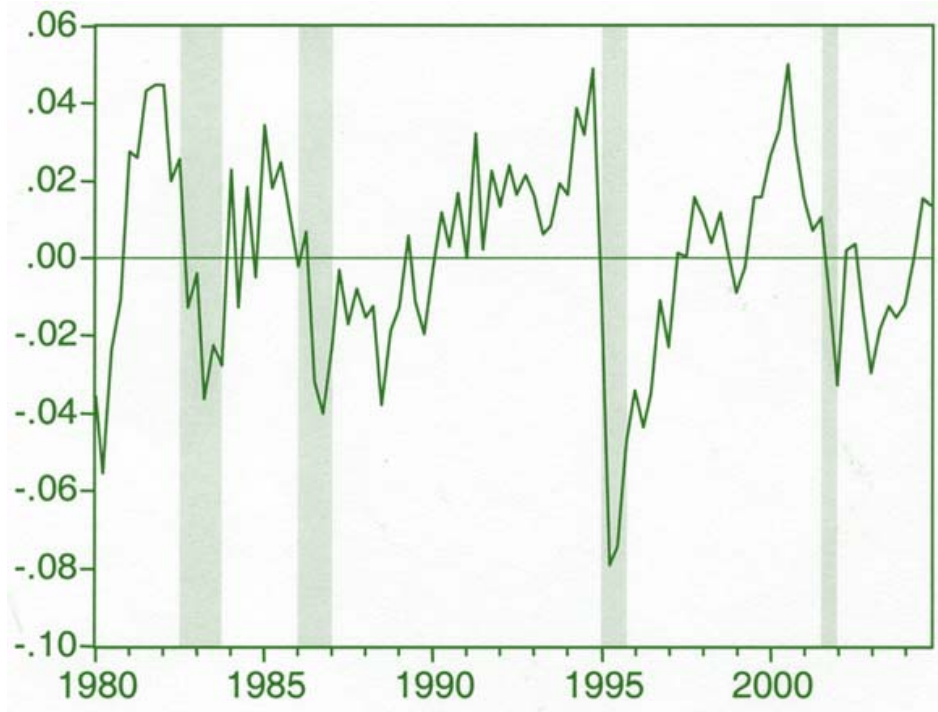

Gráfica 2.

Ciclo económico del producto 
En la Gráfica 2, de manera adicional, con bloques verticales de color verde tenue se denotan los periodos de recesión por los que ha pasado el país; dichos momentos se establecieron usando el criterio que determina que una variación negativa del PIB trimestral de un año con respecto de otro que se prolonga por más de tres trimestres puede ser considerado un periodo de recesión económica.

En los cuatro casos se puede apreciar que el ciclo económico coincide con los periodos recesivos. Ya que se tienen las fluctuaciones cíclicas del producto se puede proceder a determinar la postura de la política fiscal ante tales fluctuaciones.

Las series de datos fiscales que se utilizarán para determinar el comportamiento de la política fiscal ante el ciclo económico son dos por el lado del ingreso y dos más por el lado del gasto. En el primer caso se usaron los ingresos totales del sector público y los ingresos totales tributarios, mientras que por el lado del gasto se emplearon los gastos totales del sector público y los gastos totales primarios. Todas las series se dan en términos reales, es decir, deflactadas, ${ }^{30}$ en logaritmos, desestacionalizadas y, al igual que para el PIB, se utilizó el filtro de Hodrick y Prescott para determinar su comportamiento cíclico y los resultados se pueden apreciar en las gráficas 3, 4, 5 y 6.

Con las series obtenidas de los ciclos de todas las variables y siguiendo a Fiorito y Kollintzas (1993), podemos determinar si la postura fiscal durante el periodo fue procíclica o contracíclica, atendiendo las siguientes consideraciones.

\begin{tabular}{lll}
\hline $\mathrm{Si}$ & $0 \leq \mid \rho(t+i) \leq 0.2$ & Acíclica \\
$\mathrm{Si}$ & $\rho(t-i) \geq 0.2$ & Procíclica \\
$\mathrm{Si}$ & $\rho(t-i) \leq-0.2$ & Contracíclica \\
\hline
\end{tabular}

en las cuales $\rho(t-1)$ es el coeficiente de correlación. Y adicionalmente:

\begin{tabular}{lll}
\hline $\mathrm{Si}$ & $0.5 \leq \mid \rho(t+i) \leq 1$ & La correlación se considera fuerte \\
$\mathrm{o} \mathrm{Si}$ & $0.2 \leq \mid \rho(t+i) \leq 0.5$ & La correlación se considera débil ${ }^{\mathrm{a}}$ \\
\hline
\end{tabular}

a Para autores como Alper (2000), el coeficiente de correlación se toma como fuerte si $|p(t)|>0.65$, como débil cuando se ubica $0.30<|p(t)|<0.65$ e insignificante cuando $|p(t)|<0.30$.

Del Cuadro 2 se tiene que en todo el periodo, es decir, 1980-2004, tres de las cuatro variables fiscales resultaron procíclicas, destacándose aquella que refiere los gastos de no pago de intereses que adicionalmente está fuertemente correlacionada

30 Con el deflactor del PIB. 
Cuadro 1

\begin{tabular}{|c|c|c|c|c|c|}
\hline & 1980-1984 & $\begin{array}{r}P \\
1985-1989\end{array}$ & 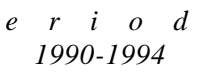 & $\begin{array}{l}o \\
1995-1999\end{array}$ & 2000-2004 \\
\hline Ingresos totales & -0.34 & 0.42 & 0.26 & 0.41 & 0.29 \\
\hline Ingresos tributarios & 0.14 & -0.34 & 0.40 & 0.86 & -0.31 \\
\hline Gasto total & 0.60 & -0.18 & 0.24 & 0.49 & 0.38 \\
\hline $\begin{array}{l}\text { Gasto de no pago } \\
\text { de intereses }\end{array}$ & 0.78 & 0.22 & 0.39 & 0.78 & 0.06 \\
\hline
\end{tabular}

Cuadro 2

\begin{tabular}{lcccccc}
\hline & & $P$ & $e$ & $i$ & $o$ & $d$ \\
& $1980-1989$ & $1990-1999$ & $2000-2004$ & $1980-2004$ \\
\hline Ingresos totales & -0.05 & 0.37 & 0.29 & 0.19 \\
Ingresos tributarios & -0.01 & 0.80 & -0.31 & 0.36 \\
Gasto total & 0.29 & 0.28 & 0.38 & 0.28 \\
Gasto de no pago de intereses & 0.54 & 0.68 & 0.06 & 0.53 \\
\hline
\end{tabular}

con los movimientos del producto. Por su parte, los ingresos totales se presentan ligeramente acíclicos. ${ }^{31}$

Se detecta en el Cuadro 1 que los ingresos tributarios en dos de los cinco periodos han sido contracíclicos (1985-1989, 2000-2004), incluso cuando su correlación tiende a ser débil.

También es destacable que los ingresos del sector público en la década de los años ochenta en su conjunto tuvieron un comportamiento acíclico.

Lo anterior aun cuando se trata de un análisis rudimental consistente en una serie de cuestionamientos que se hacen al respecto de la postura fiscal en países latinoamericanos o en desarrollo, y en el caso específico de México a la descripción que hace Huerta (2004a:140), quien argumenta que el carácter procíclico de la política fiscal conduce a un callejón sin salida al no generar opciones de crecimiento económico.

31 Ante las posibles alteraciones que pudieran tener los resultados por la existencia de valores atípicos, se hicieron diferentes estimaciones excluyendo, corrigiendo o reexpresando dichos valores, sin obtener cambios significativos en los resultados, derivado de ello y por cuestiones de espacio no se presentan las estimaciones mencionadas. 


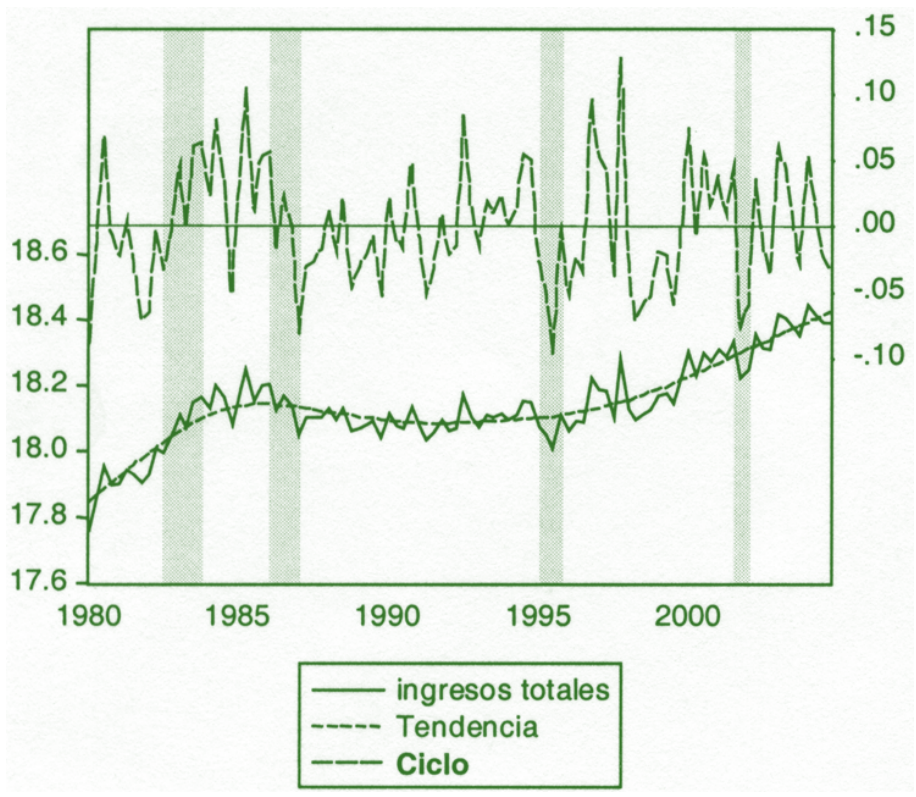

Gráfica 3.

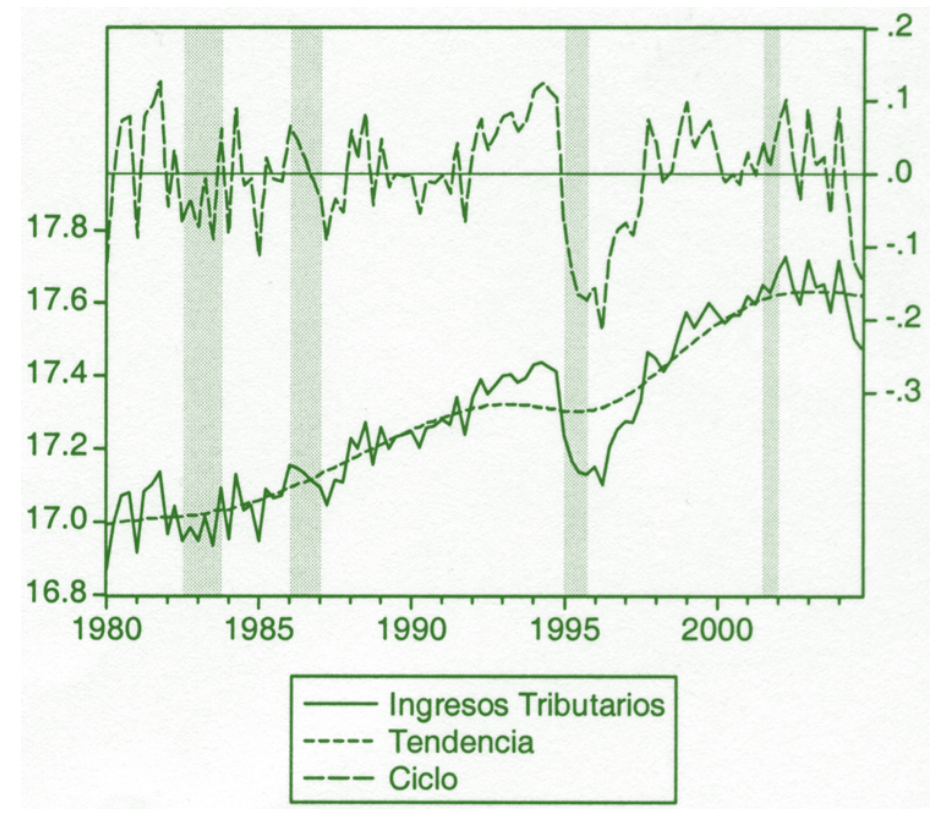

Gráfica 4. 


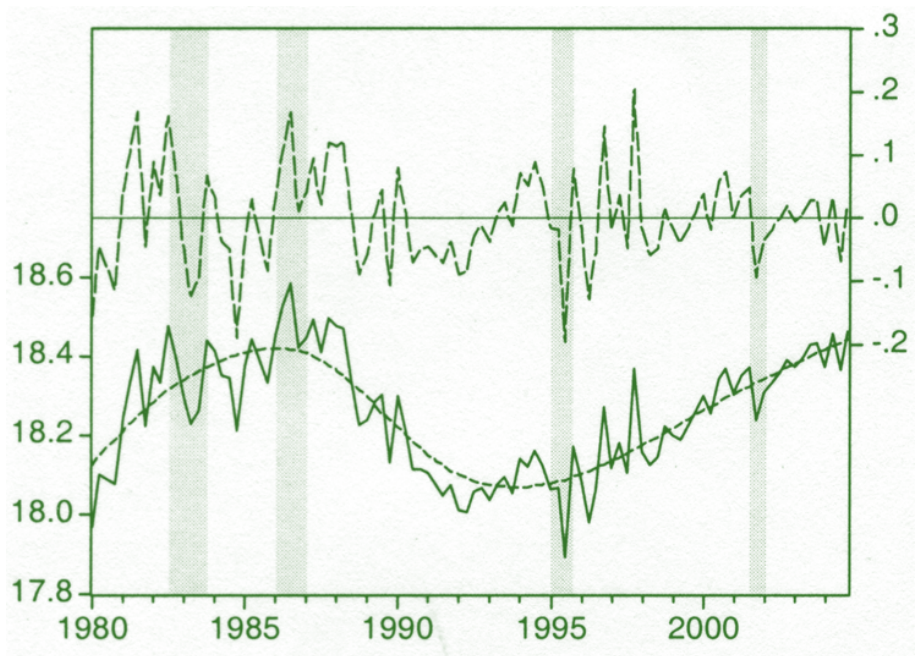

Gráfica 5.

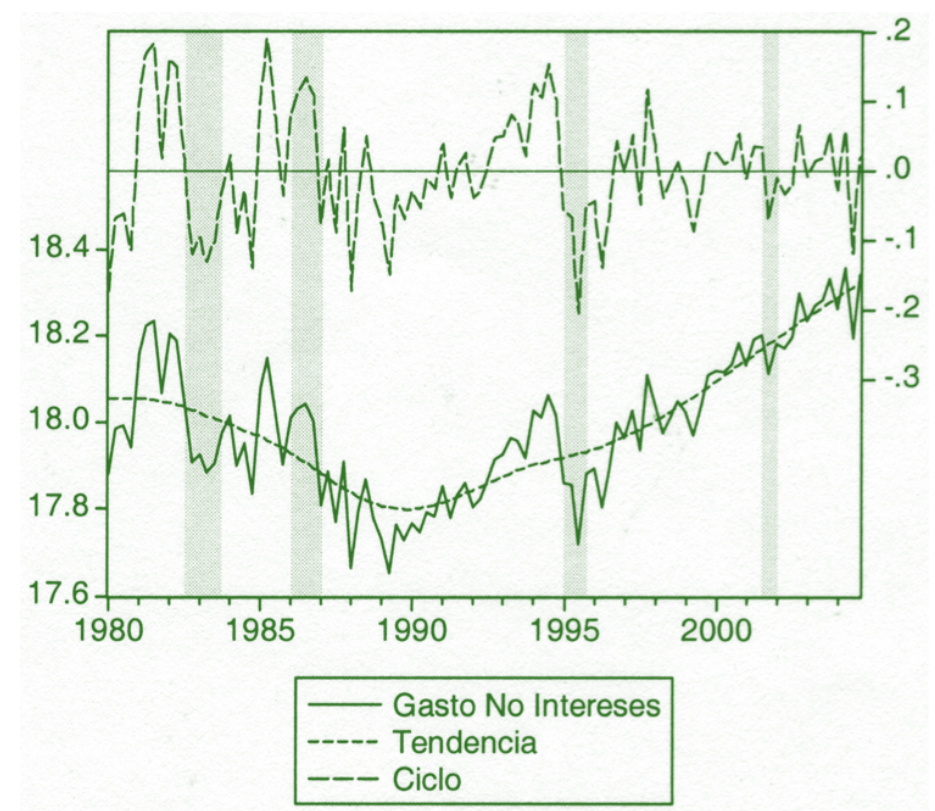

Gráfica 6. 
Alesina, Alberto y Guido Tabellini, "Why is fiscal often procyclical?", Working Paper, núm. 11600, Massachusetts, NBER, septiembre 2005.

Alper C., Emre, "Stylized Facts of Business Cycles, Excess Volatility and Capital Flows: Evidence from Mexico and Turkey", www.econ.boun.edu.tr/papers/pdf/wp-0011.pdf, 2000.

Arestis, Philip y Malcolm Sawyer, "Reinventing Fiscal Policy", Working Paper, núm. 381, Nueva York, The Levy Economics Institute of Bard College, mayo, 2003.

Auerbach, Alan y Daniel Feenberg, "The Significance of Federal Taxes as Automatic Stabilizers", en Journal of Economics Perspectives, vol. 14, núm. 3, Nashville, American Economic Association, verano, 2000, pp. 37-56.

Bell, Stephanie y Randall Wray, "Financial Aspect of the Social Security Problem", Working Paper, núm. 5, Kansas City, Center for Full Employment and Price Stability, University of Missouri-Kansas City, enero, 2000.

Bell, Stephanie, "Can Taxes and Bonds Finance Government Spending?", Working Paper, núm. 244, Nueva York, The Levy Economics Institute of Bard College, julio, 1998.

Birdsall, Nancy, et al., "Washington Contentious Economic Policies for Social Equity in Latin America", en Findings of the Commission on Economic Reform in Unequal Latin American Societies sponsored, Massachusetts, The Carnegie Endowment for International Peace and the Inter American Dialogue, 2001.

Braconier, Henrik y Tomas Forsfält, "A New Method for Constructing a Cyclically Adjusted Budget Balance: The Case of Sweden", Working Paper, núm. 90, Estocolmo, The National Institute of Economic Research, abril, 2004.

Braun, Miguel y Luciano Di Gresia, "Towards Effective Social Insurance in Latin America: The Importance of Countercyclical Fiscal Policy”, Working Paper, núm. 487, Nueva York, BID, marzo, 2003.

Budnevich, Carlos, "Countercyclical Fiscal Policy, A Review of the Literature Empirical Evidence and Some Policy Proposals", Discussion Paper, núm. 2002/41, Helsinki, WIDER, 2002.

Camara-Neto, Alcino y Matias Vernengo, "Fiscal Policy and the Washington Consensus, A
Post-Keynesian Perspective", Working Paper, núm. 9, Utha, University Utha, Deparment of Economics, 2004.

Clavijo, Fernando, Reformas Económicas en México 1982-1999, serie Lecturas, núm. 92, México, FCE, 2000.

Cohen, Darrel y Glenn Follette, "The Automatic Fiscal Stabilizers: Quietly Doing Their Thing", en Economic Policy Review, Nueva York, Federal Reserve Bank of New York, abril, 2000

Davidson, Paul, "Is Fixed Exchange Rates The Problem and Flexible Exchange Rates the Cure", en The Eastern Economic Journal, vol. 29, Nueva York, primavera, 2003.

Diebold, Francis y Glenn Rudebusch, "Measuring Business Cycles: A Modern Perspective", en Review of Economics and Statistics, vol. LXXVIII, núm. 1, Cambridge, MIT, febrero, 1996, pp. 67-77

Dornbusch, Rudiger y Stanley Fischer, Macroeconomía, Madrid, McGrawHill, 1994.

Emre, Ousel y Manmohan Kumar, "Procyclicality of Fiscal Policy in Emerging Market: The Role of Uncertainty, Productivity Shocks and Capital Flows", forthcoming IMF working paper, 2005.

Ffrench-Davis, Ricardo, "Reforming the Reforms of the Washington Consensus for Achieving Growth and Equity", American Program, Center for Strategic and International Studies, junio, 2003.

Fiorito, Riccardo y Tryphon Kollintzas, "Stylized facts of business cycles in the G7 from a real business cycle Perspective", en European Economic Review, vol. 38, issue 2, Elsevier, febrero, 1994, pp. 235-269.

Forstater, Mathew, "Public Employment and Economic Flexibility, The Job Opportunity Approach to Full Employment", en Public Policy Brief, núm. 50, Nueva York, The Levy Economics Institute of Bard College, 1999. -, "The Case for an Environmentally Sustainable Jobs Program", en Policy Note, núm. 2005/1, Nueva York, The Levy Economics Institute of Bard College, enero, 2005.

Gavin, Michael y Roberto Perotti, "Fiscal Policy in Latin America", en NBER Microeconomics Annual 1997, Massachusetts, NBER, 1997.

Hansen, Alvin, Política Fiscal y Ciclo Económico, México, FCE, 1966.

Hodrick, Robert y Edward Prescott, "Postwar U.S. Business Cycles: An Empirical 
Investigation", en Journal of Money, Credit, and Banking, vol. 29, The Ohio State University Press, febrero, 1997.

Huerta, Arturo, La economía Política del Estancamiento, México, Diana, 2004a.

-, Las reformas estructurales y su incapacidad de alcanzar el crecimiento sostenido, mimeo 2004b.

Kalecki, Michal, Teoría de la Dinámica Económica, ensayos sobre los movimientos cíclicos y a largo plazo de la economía capitalista, México, FCE, 1984.

Kattai, Rasmus, et al., "Automatic Fiscal Stabilizers in Estonia: The Impact of Economic Fluctuations on General Government Budget Balance”, Working Paper, núm.03/ 11, Estonia, Bank of Estonia, 2003.

Keynes, John M., Teoría general de la ocupación, el interés y el dinero, México, FCE, 2003.

Lerner, Abba P., Economía del Pleno Empleo, Madrid, Aguilar, 1957.

Lora, Eduardo et al., "Reform Fatigue: Symptoms, Reasons and Implications", en Economic Review, segundo trimestre, Atlanta, Federal Reserve Bank of Atlanta, 2004.

Lora, Eduardo y Ugo Panizza, "Globalización y Reformas Estructurales en América Latina: Lo que Funcionó y lo que no", en Revista Asturiana de Economía (RAE), núm. 24, Asturias, 2002.

Miller, Shirley, "Métodos alternativos para la medición del PIB potencial: una aplicación para el caso del Perú", en Estudios Económicos, núm 10, Perú, Banco Central de Reserva del Perú, mayo, 2003.

Mitchell, William, "The Job Guarantee Model and the NAIRU", Working Paper, núm. 9801, Australia, Australia Centre of Full Employment and Equity, The University of Newcastle, enero, 1998.

Mohanty, Madhusudan y Michela Scatigna, "Countercyclical fiscal policy and central banks", BIS Papers, núm. 20, Fiscal issues and central banking in emerging economies, Bank for International Settlement, octubre, 2003.

Mosler, Warren y Mathew Forstater, "The Natural Rate of Interest is Zero", Working Paper, núm. 37, Kansas City, Center for Full Employment and Price Stability, University of Missouri-Kansas City, diciembre, 2004.

Ocampo, José "Más allá del Consenso de Washington: una agenda de desarrollo para América Latina", en Serie Estudios y Perspectiva, núm. 26, Santiago de Chile, CEPAL, enero, 2005.
"Retomar la agenda del desarro1lo", en Revista de la CEPAL 74, Santiago de Chile, agosto, 2001.

Panizza, Ugo y Mónica Yañez, "Why are Latin Americans so Unhappy about Reforms", en Journal Applied Econúmmics, vol. viII, núm. 1, Argentina, UCEMA, mayo, 2005, pág. 1-29.

Ramírez, Eduardo, "El Gobierno como empleador de última instancia: una alternativa de programa público de empleo", en Problemas del Desarrollo, Revista Latinoamericana de Economía, vol. 37, núm. 144, México, IIECUNAM, 2006.

Romero, José, "Expansión monetaria y crecimiento económico: una visión alternativa", Documento de Trabajo, núm. vII, México, El Colegio de México, Centro de Estudios Económicos, 1999.

Sanchez, Omar, "Globalization as a Development Strategy in Latin America?", World Development, vol. 31, núm. 12, Elsevier, 2003.

Sawyer, Malcolm, "On Budget Deficits and Capital Expenditure", Working Paper, núm. 208, Nueva York, The Levy Economics Institute of Bard College, octubre, 1997.

Seccareccia, Mario, "What Type Full Employment? A critical Evaluation of "Government as the Employer of Last Resort" Policy Proposal", en Investigación Económica, vol. LXIII, 247, México, Revista de la Facultad de Economía de la UNAM, enero-marzo, 2004.

Stiglitz, Joseph, "El Rumbo de las Reformas, Hacia una Nueva Agenda para América Latina", en Revista de la CEPAL, núm. 80, Santiago de Chile, agosto, 2003.

Talvi, Ernesto y Carlos Végh, "Tax Base Variability and Procyclical Fiscal Policy", Working Paper, núm. 7499, Massachusetts, NBER, enero, 2000.

Tam, Julie y Heather Kirkham, "Automatic Fiscal Stabilisers: Implications for New Zealand", Working Paper, núm. 01/10, Nueva Zelanda, New Zeland Treasury, octubre, 2001.

Weeks, John y Rathin Roy, "Making Fiscal Policy Work for the Poor", http://www.eldis. org/static/DOC20277.htm, enero, 2004.

Willianson, John, "The Washington Consensus as Policy Prescription for Development", A lecture in the series "Practioners of Development" delivered at the World Bank, Massachusetts, IIE, enero 2004a.

,"A short History of the Washington Consensus", Paper Commissioned by a Foundation CIDOB for a Conference "From the Washington Consensus Towards a new Global Governance", Barcelona, septiembre, $2004 b$. 
Wray, Randall, "Abolish the Surplus", http:// www.mosler.org/docs/docs/abolish_the_ surplus.htm, septiembre, 1999.

"Funtional Finance and us Government Budget Surpluses in The New Millenium", http://www.mosler.org/docs/docs/functional finance.htm, febrero, 2000.

"Currency Sovereignty and the Possibility of Full Employment", Working Paper, núm. 28, Kansas City, Center for Full
Employment and Price Stability, University of Missouri-Kansas City, agosto, 2003.

"International Aspects of Current Monetary Policy", Working Paper Núm. 31, Kansas City Center for Full Employment and Price Stability, University of MissouriKansas City, marzo, 2004.

,"A Primer on Government Surplus", Special Report 00/02, http://www.cfeps.org/ pubs/sr/sr0002/, 2002. 


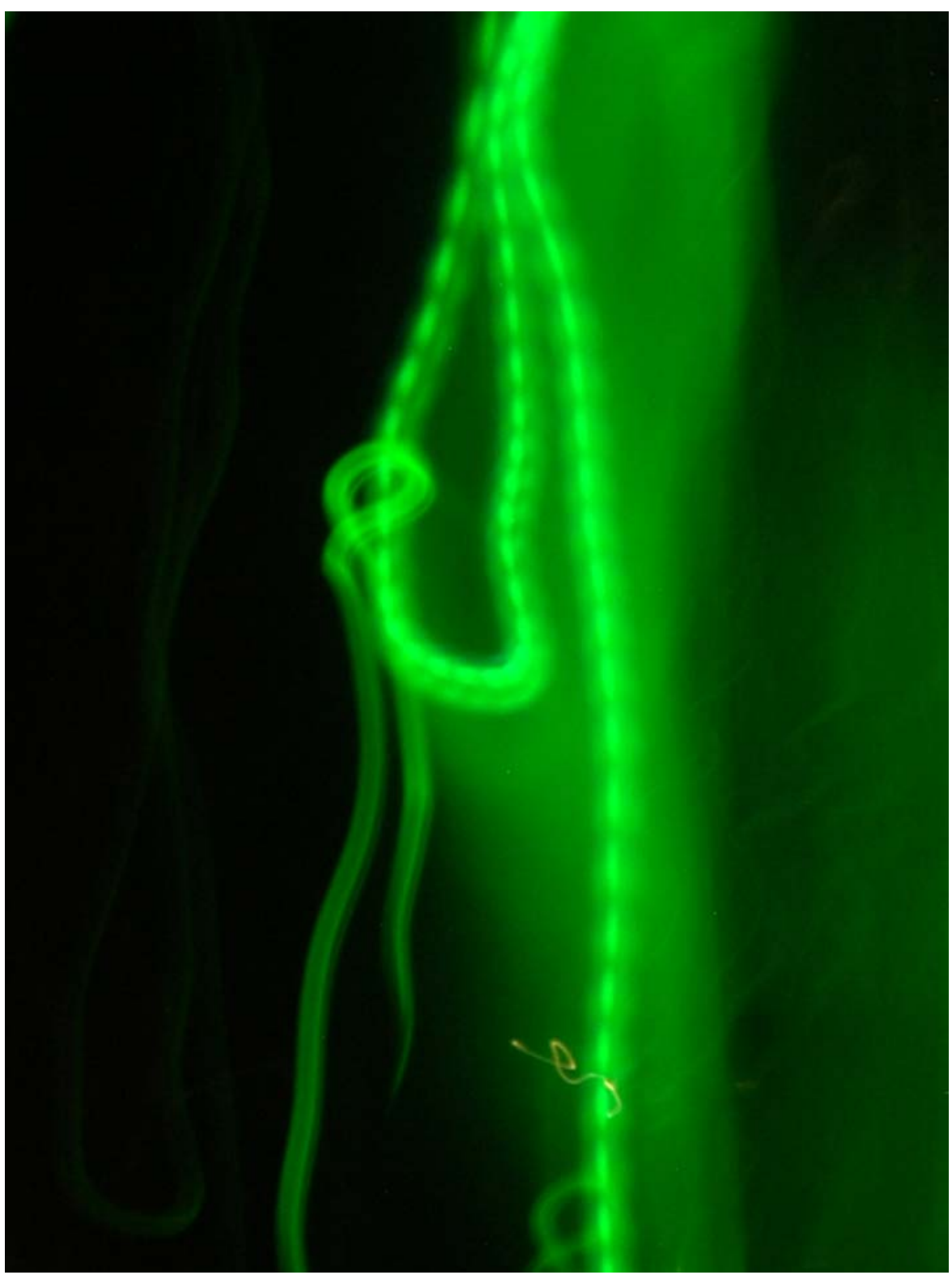

Ínfulas de analizadores lumínicos, Viteh, 2006. 